\title{
The Impact of the Assimilation of Dropsonde Observations during PALAU2005 in ALERA
}

\author{
Qoosaku Moteki ${ }^{1}$, Ryuichi Shirooka ${ }^{1}$, Kunio Yoneyama ${ }^{1}$, Biao Geng ${ }^{1}$, Masaki Katsumata ${ }^{1}$, \\ Tomoki Ushiyamaㄹ, Hiroyuki Yamada ${ }^{1}$, Kazuaki Yasunaga ${ }^{1}$, Naoki Sato ${ }^{1}$, Hisayuki Kubota ${ }^{1}$, \\ Krishnaredikari Krishna Reddy ${ }^{1}$, Hiroki Tokinaga ${ }^{1}$, Ayako Seiki ${ }^{1}$, Mikiko Fujita ${ }^{1}$, \\ Yukari N. Takayabu ${ }^{1,2}$, Masanori Yoshizaki ${ }^{1}$, Hiroshi Uyeda ${ }^{3}$, and Takashi Chuda ${ }^{4}$ \\ ${ }^{1}$ Institute of Observational Research for Global Change, JAMSTEC, Yokosuka, Japan \\ ${ }^{2}$ Center of Climate System Research, the University of Tokyo, Kashiwa, Japan \\ ${ }^{3}$ Hydrospheric Atmospheric Research Center, Nagoya University, Nagoya, Japan \\ ${ }^{4}$ Ocean Research Institute, the University of Tokyo, Tokyo, Japan
}

\begin{abstract}
The effect of the assimilation of dropsonde data over the tropical western Pacific was investigated in an objective analysis. In June 2005, 30 dropsondes were released on four separate flight days. The data impact was assessed using the objective analysis dataset of "ALERA." The analysis of the zonal wind field over the tropical western Pacific in ALERA revealed large errors corresponding to active convection. These errors were reduced by $1-3 \mathrm{~m} \mathrm{~s}^{-1}$ due to the assimilation of the dropsondes. The impact signal due to the assimilation of the dropsondes propagated northward and appeared significantly around Japan. The phase and group speeds of the impact signal at $700 \mathrm{hPa}$ were approximately $3 \mathrm{~m}$ $\mathrm{s}^{-1}$ and $12 \mathrm{~m} \mathrm{~s}^{-1}$, respectively. The former speed was consistent with the mean meridional wind speed, and the latter speed roughly corresponded to the meridional group speed of Rossby waves with wavelengths of a few thousand kilometers.
\end{abstract}

\section{Introduction}

Relatively large errors in the analysis of operational observation-sparse regions significantly affect the uncertainty in numerical forecasts over downstream regions. In mid-latitudes, the impact of dropsondes over oceans on analysis-forecast errors in downstream regions has been investigated by several researchers (Langland et al. 1999; Szunyogh et al. 1999; Szunyogh et al. 2000; Szunyogh et al. 2002). For instance, Szunyogh et al. (2002) have reported that the impact of dropsonde observations over the North Pacific propagated at a speed of $30^{\circ}-40^{\circ}$ per day.

However, in tropics, challenges in such sensitivity experiments are still rare (e.g., Majumdar et al. 2006). According to statistical studies, convective activities over the tropical western Pacific have a significant impact on those around Japan (termed "PJ" pattern, Nitta 1987). High-impact weather events on the western coast of North America are sometimes caused in association with the generation of tropical cyclones over the tropical western Pacific. The hypothesis that such a phenomenon is connected with Rossby wave trains generated over the Pacific is the underlying focus of the observing system research and predictability experiment (THORPEX, Toth and Majumdar 2007) Pacific-

Corresponding author: Qoosaku Moteki, Institute of Observational Research for Global Change (IORGC), Japan Agency for Marine-Earth Science and Technology, 2-15 Natsushima-cho, Yokosuka 237-0061, Japan. E-mail: moteki@jamstec.go.jp. (C)2007, the Meteorological Society of Japan.
Asian regional campaign (T-PARC) planned in 2008.

From the viewpoint of the research on the predictability of high-impact events in the mid-latitudes, the assessment of the impact of additional observations over tropics on the mid-latitudes is also an important issue. The IORGC/JAMSTEC has conducted an intensive observation project in 2005 known as the Pacific area long-term atmospheric observation for understanding of climate change (PALAU2005, Moteki et al. 2007). During PALAU2005, dropsonde observations were conducted using a Gulfstream II aircraft on 12, 13, 15, and 17 June 2005. The present study evaluates the effect of the dropsonde observations in AFES-LETKF experimental reanalysis (ALERA, Miyoshi et al. 2007) and describes the propagation of its impact signal. The ALERA is an experimental reanalysis dataset produced by AGCM for the Earth Simulator (AFES, Ohfuchi et al. 2004)-four dimensional local ensemble transform Kalman filter (LETKF, Miyoshi and Yamane 2007) system. The outline of the dropsonde observations and ALERA products are described in section 2. Section 3 presents the propagation of the effect of the dropsonde observations. The summary is provided in section 4 .

\section{Description of dropsonde observations and ALERA}

\subsection{Flight missions}

Dropsonde observations (wind, temperature, humidity, and pressure) over the tropical western Pacific were conducted on 12, 13, 15, and 17 June 2005 as part of PALAU2005 (Fig. 1). In all, 30 dropsondes were released from altitudes varying from 9 to $11 \mathrm{~km}(200-300 \mathrm{hPa})$ around convective systems associated with the intertropical convergence zone (ITCZ) and tropical waves. During the period of 12-17 June, active convections in the Baiu frontal zone that slowly moved northward were observed continuously up to a few thousand kilometers north of the dropsonde observation area.

\subsection{ALERA dataset}

The ALERA dataset was generated by an analysis cycle using a 40-member ensemble forecast with AFES 2.2 (Enomoto et al. 2006) at a T159/L48 resolution for the period from May 2005 to October 2006. The assimilated observations are adapted from the operational numerical weather prediction system of the Japan Meteorological Agency (JMA). It should be noted that satellite observations with the exception of satellitebased wind data are not assimilated because of technical problems. Miyoshi et al. (2007) confirmed that the accuracy of ALERA is comparable to those of the JMA operational analysis and National Centers for Environ- 

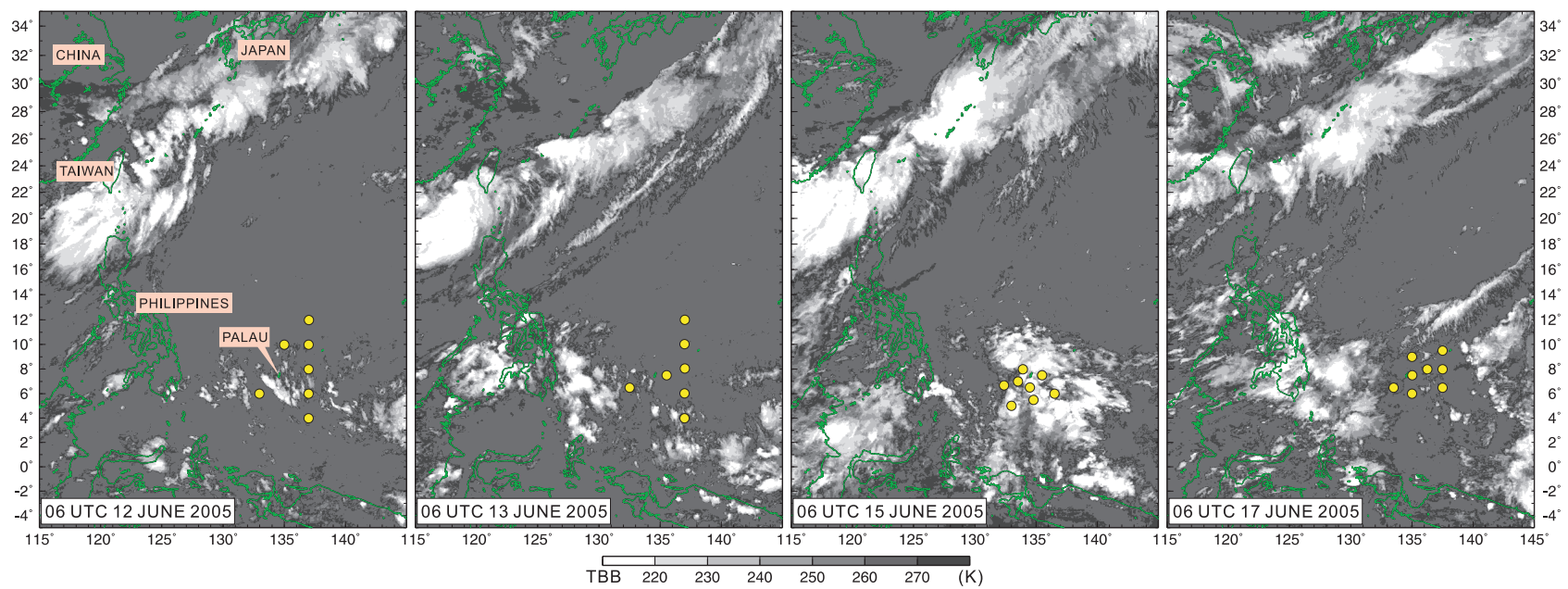

Fig. 1. Infrared satellite images at 06 UTC on 12, 13, 15, and 17 June 2005. The open yellow circles represent the locations of the dropsondes.
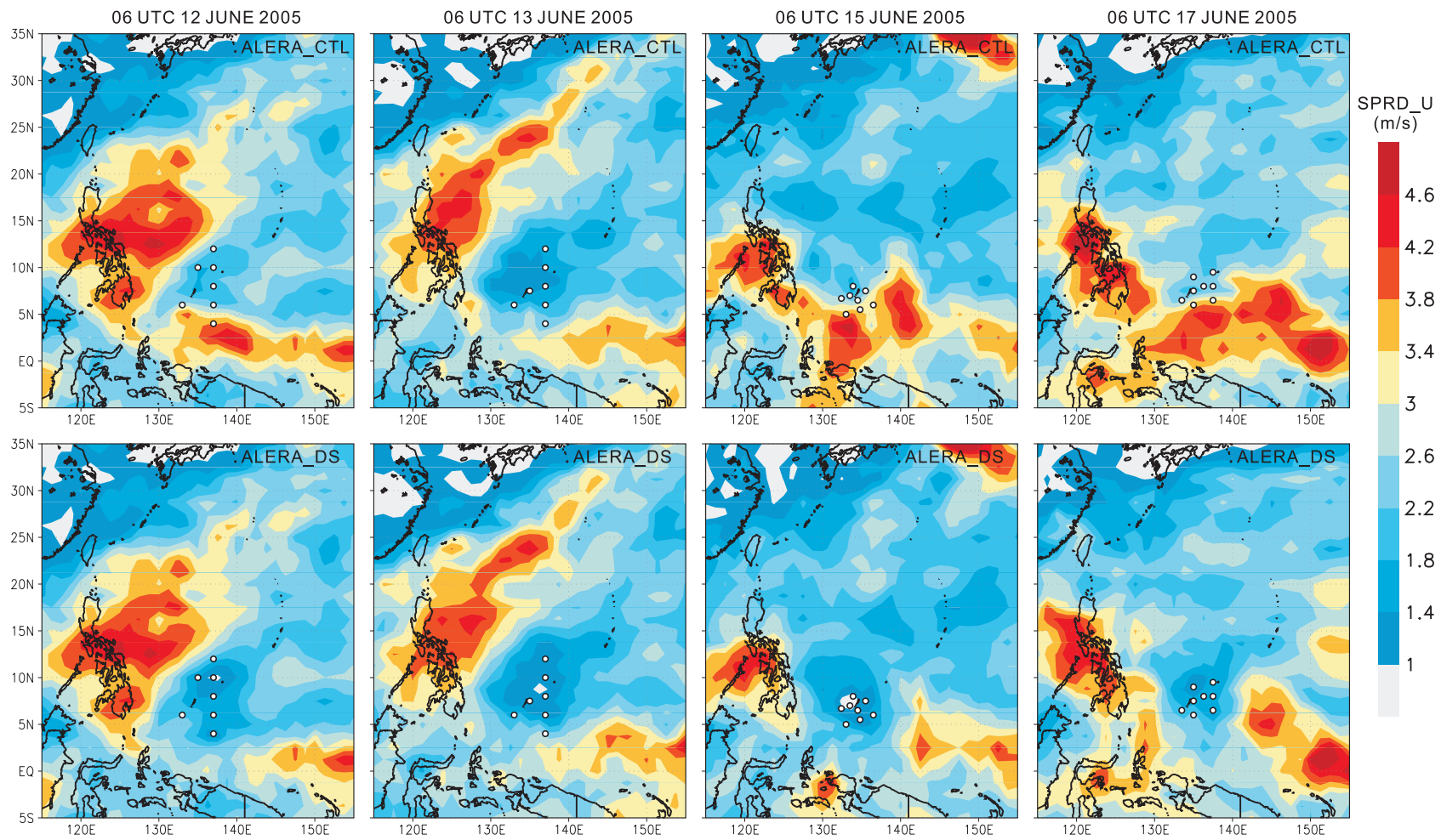

Fig. 2. ALERA_CTL (top) and ALERA_DS (bottom) depicting analysis ensemble spread of zonal wind speed at 700 $\mathrm{hPa}$ at $06 \mathrm{UTC}$ on $12,13,15$, and 17 June 2005 . The open circles represent the locations of the dropsondes.

mental Prediction/National Center for Atmospheric Research (NCEP/NCAR) reanalysis except for the upper atmosphere above $30 \mathrm{hPa}$ and Southern Hemisphere high latitudes.

In this study, the datasets of ALERA with and without the assimilation of the dropsonde data (hereafter referred to as ALERA_DS and ALERA_CTL, respectively) were used. These products include the analysis ensemble mean and analysis ensemble spread of wind, temperature, humidity, and geopotential height at 17 pressure levels between $10-1000 \mathrm{hPa}$. As for the assimilation of the dropsondes, observation errors of 4 $\mathrm{m} \mathrm{s}^{-1}$ for wind, $1.5 \mathrm{~K}$ for temperature, $30 \%$ for relative humidity, and $1.0 \mathrm{hPa}$ for pressure are used.

\section{Effect of dropsonde observations}

With ALERA CTL, the spread over the tropical western Pacific is generally larger than that over other regions, and the effect of the dropsondes on winds between $400-850 \mathrm{hPa}$ is relatively greater than the 
DIFF_U (700hPa) 1-DAY AVE. 13 JUNE 2005
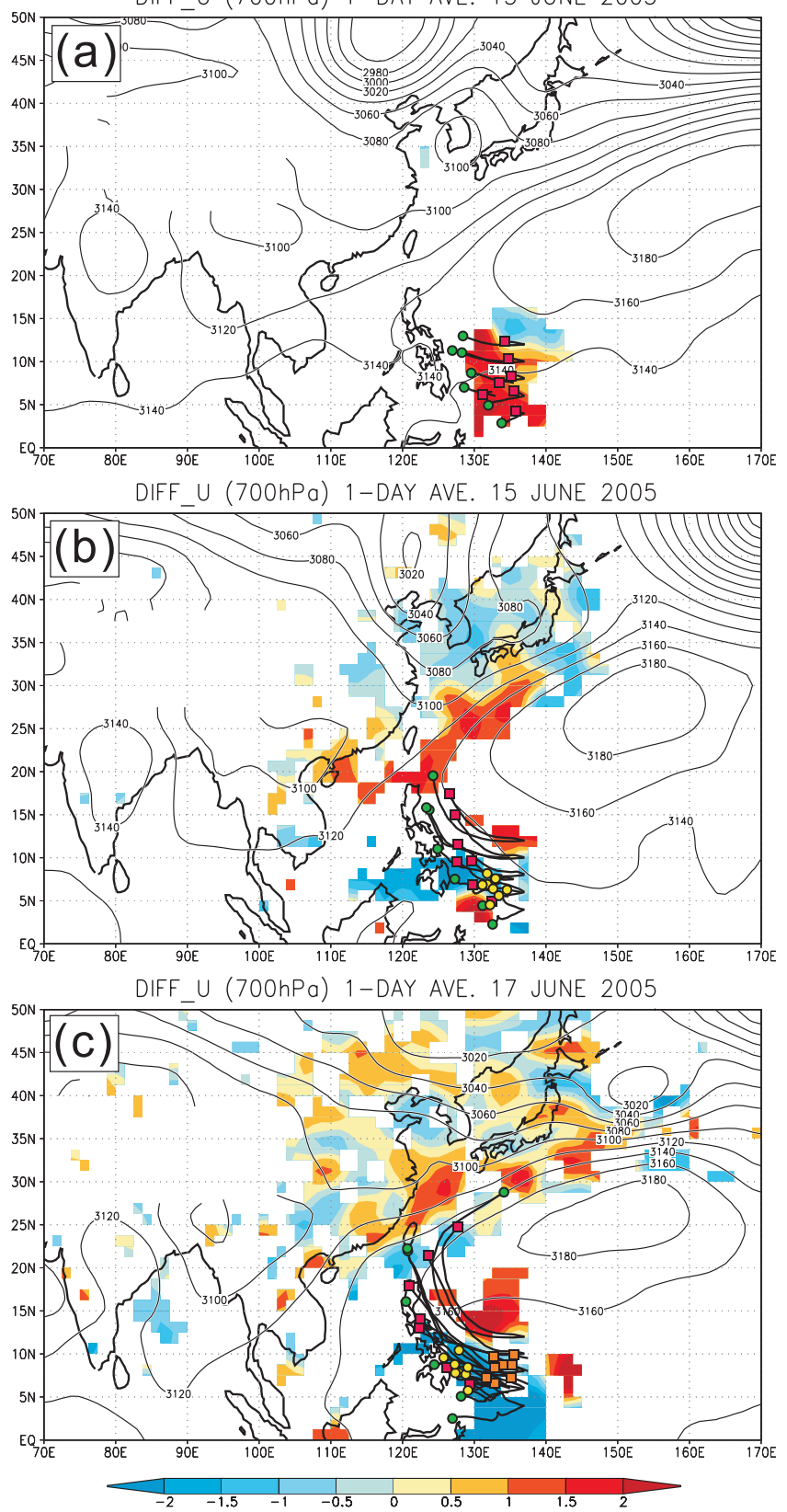

Fig. 3. One-day-averaged impact signal (difference between the two datasets with t-test significance level more than 95\%) of zonal wind speed and geopotential height at $700 \mathrm{hPa}$ on (a) 13, (b) 15, and (c) 17 June 2005. The green circles, purple rectangles, yellow circles, and orange rectangles represent the positions of the air parcels advected from dropsonde locations on 12, 13, 15, and 17 June, respectively.

effect on other variables (not shown). Figure 2 shows the analysis spread of zonal wind speed with ALERA CTL and ALERA DS at $700 \mathrm{hPa}$ at 06 UTC on 12, 13, 15, and 17 June. Over the tropical western Pacific, the large spread region with ALERA CTL corresponds well with convective areas shown in Fig. 1, while in ALERA DS, the spread in a square region of approximately $1000 \mathrm{~km}$ in the vicinity of Palau is reduced by $1-3 \mathrm{~m} \mathrm{~s}^{-1}$. Considering the zonal wind speed of $2-5 \mathrm{~m}$

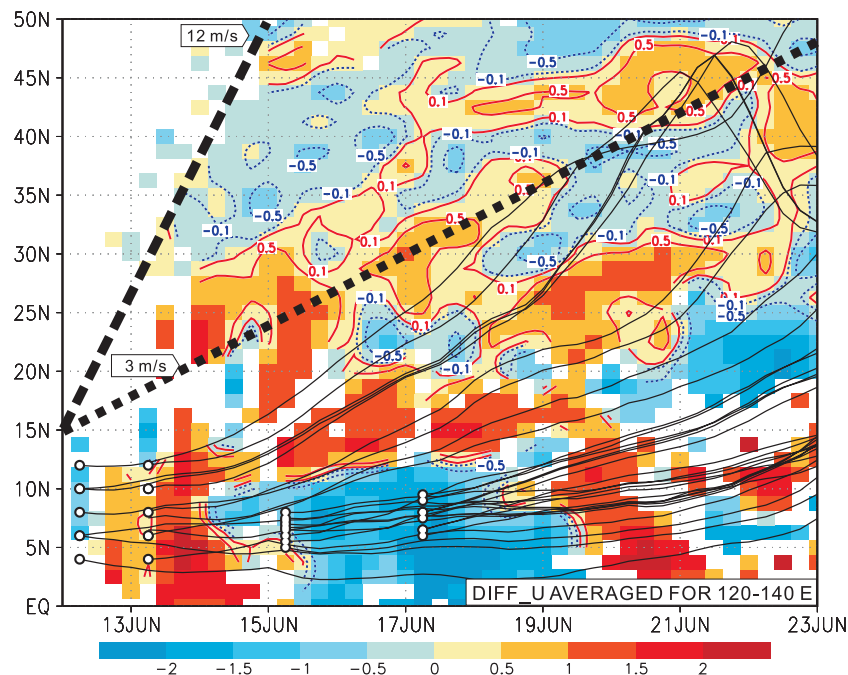

Fig. 4. Time-latitude cross section of impact signal of zonal wind speed averaged for $120-140^{\circ} \mathrm{E}$. The bold dashed and dotted lines indicate the northwardpropagation speed of 12 and $3 \mathrm{~m} \mathrm{~s}^{-1}$, respectively. The open circles indicate the locations of the dropsondes. The trajectories of the air parcels advected from dropsonde locations on 12,13, 15, and 17 June are indicated by the black lines.

$\mathrm{s}^{-1}$ in the region, this decrease in the spread is very significant. It is expected that such a significant effect of the dropsondes on the analysis propagates through advection and atmospheric wave propagation. In this study, a t-test was performed for obtaining the significant difference between the ensemble mean values of ALERA_CTL and ALERA_DS using the analysis spreads as variance at a significant level of greater than $95 \%$.

Figure 3 shows the one-day-averaged field of the impact signal (i.e., the significant difference) of the zonal wind speed. Until 13 June, the strong impact signal was concentrated in the region where air parcels advected from dropsonde locations can reach (Fig. 3a). After 14 June, the signal propagated northward and appeared around Japan (Figs. 3b and 3c). Its propagation speed was clearly greater than that of the advection of the air parcels at $700 \mathrm{hPa}$. As reported in the previous studies (e.g., Szunyogh et al. 2002; Hakim 2005), it is suggested that such a rapid propagation of the signal is due to the propagation of energy associated with the atmospheric waves and their vertical interaction. In addition, after 14 June, the signal appeared in the Baiu frontal zone and the vicinity of the trough to the north. This is consistent with the observations in previous studies, in which the strong signal tended to appear in the region of strong baroclinicity (Szunyogh et al. 2002).

Figure 4 shows the time-latitude cross section of the impact signal of the zonal wind speed averaged for $120^{\circ}-140^{\circ} \mathrm{E}$. The meridional phase speed of the signal is approximately $3 \mathrm{~m} \mathrm{~s}^{-1}$, and it is roughly consistent with the speed of the advection of the air parcels from the dropsonde locations. The meridional group speed of the signal is approximately $12 \mathrm{~m} \mathrm{~s}^{-1}$ and it is almost the same in all layers. It roughly corresponds to the group speed of the Rossby waves with wavelengths of 3500$4000 \mathrm{~km}$ in the meridional direction and $6000-8000 \mathrm{~km}$ in the zonal direction. 


\section{Summary}

The propagation of the effect of dropsonde observations over the tropical western Pacific was investigated in ALERA. Thirty dropsondes used in this study were released on four separate flight days in June 2005. The data impact was assessed by comparing the datasets of ALERA with and without the assimilation of the dropsonde data (termed ALERA_DS and ALERA_CTL, respectively).

Large errors in the analysis of zonal wind speed corresponding to active convection over the tropical western Pacific were reduced by $1-3 \mathrm{~m} \mathrm{~s}^{-1}$ due to the assimilation of the dropsondes. The impact signal of the assimilation propagated northward and appeared significantly around Japan. The phase and group speeds of the impact signal at $700 \mathrm{hPa}$ were approximately $3 \mathrm{~m}$ $\mathrm{s}^{-1}$ and $12 \mathrm{~m} \mathrm{~s}^{-1}$, respectively. The former speed was consistent with the mean meridional wind speed. The latter speed roughly corresponded to the meridional group speed of Rossby waves with wavelengths of 3500-4000 $\mathrm{km}$ in the meridional direction and $6000-8000 \mathrm{~km}$ in the zonal direction.

On the basis of the preliminary results presented in this study, detailed analyses of waves that prevail in the tropical western Pacific are expected in the future. It is desirable to investigate the effects of additional observation data and the propagation of these effects under varying conditions in the tropics. An understanding of the characteristics of these effects will contribute to the development of a strategy for operational observations. The IORGC/JAMSTEC has conducted intensive observation projects termed as Mirai Indian ocean cruise for the study of the MJO-convection onset (MISMO, Yoneyama et al. 2007) during the Oct.-Nov. 2006 and precipitating systems over the Indian ocean with the MJO and monsoon system: observational study (PRIMO) over the western Indian ocean during the Apr.-Jun. 2007. In addition, PALAU2008 is planned for Jun.-Jul. 2008. In the future, it is desirable to implement analyses for elucidating the characteristics of the effects of the observational data and propagation of these effects under varying conditions.

\section{Acknowledgements}

We are grateful to Dr. T. Miyoshi of the Japan Meteorological Agency, Dr. T. Enomoto of the Earth Simulator Center, JAMSTEC, and Dr. S. Yamane of the Chiba Institute of Science for providing the ALERA dataset (including ALERA_DS) generated using the Earth Simulator. We also acknowledge the staff of Diamond Air Service Co. Ltd. for operating the Gulfstream II aircraft for the dropsonde observations. Satellite-based infrared data were obtained from Kochi University. This work was supported by a Grant-in-Aid for Young Scientists (B 4402-18740304-0002) from the Japan Society for the Promotion of Science.

\section{References}

Enomoto, T., A. Yoshida, N. Komori, and W. Ohfuchi, 2006: Description of AFES 2: improvements for high-resolution and coupled simulations. High Resolution Numerical Modelling of the Atmosphere and Ocean, W. Ohfuchi and K. Hamilton (eds.), Springer, New York, (in press).

Hakim, G. J., 2005: Vertical structure of midlatitude analysis and forecast errors. Mon. Wea. Rev., 133,
$567-578$

Langland, R. H., Z. Toth, R. Gelaro, I. Szunyogh, M. A. Shapiro, S. J. Majumdar, R. E. Morss, G. D. Rohaly, C. Velden, N. Bond, and C. H. Bishop, 1999: The North Pacific Experiment (NORPEX-98): Targeted observations for improved North American weather forecasts. Bull. Amer. Meteor. Soc., 80, 1363-1384.

Majumdar, S. J., S. D. Aberson, C. H. Bishop, R. Buizza, M. S. Peng, and C. A. Reynolds, 2006: A comparison of adaptive observing guidance for Atlantic tropical cyclones. Mon. Wea. Rev., 134, 2354-2372.

Miyoshi, T., and S. Yamane, 2007: Local ensemble transform Kalman filtering with an AGCM at a T159/ L48 resolution. Mon. Wea. Rev., (in press).

Miyoshi, T., S. Yamane, and T. Enomoto, 2007: The AFES-LETKF experimental ensemble reanalysis: ALERA. SOLA , 3, 45-48.

Moteki, Q., R. Shirooka, H. Kubota, T. Ushiyama, K. K. Reddy, K. Yoneyama, M. Katsumata, N. Sato, K. Yasunaga, H. Yamada, B. Geng, M. Fujita, M. Yoshizaki, H. Uyeda, and T. Chuda, 2007: Structure and evolution of northward-propagating mesoscale convective system observed on 15 June 2005 during PALAU2005. Mon. Wea. Rev., (submitted). http://www.jamstec.go.jp/iorgc/palau/

Nitta, T., 1987: Convective activities in the tropical western Pacific and their impact on the northern hemisphere summer circulation. J. Meteor. Soc. Japan, 65, 373-390.

Ohfuchi, W., H. Nakamura, M. K. Yoshioka, T. Enomoto, K. Takaya, X. Peng, S. Yamane, T. Nishimura, Y. Kurihara, and K. Ninomiya, 2004: 10-km mesh meso-scale resolving simulations of the global atmosphere on the Earth Simulator: Preliminary outcomes of AFES (AGCM for the Earth Simulator). J. Earth Simulator, 1, 8-34.

Szunyogh, I., Z. Toth, K. A. Emanuel, C. H. Bishop, C. Snyder, R. E. Morss, J. Woolen, and T. Marchok, 1999: Ensemble-based targeting experiments during FASTEX: The effect of dropsonde data from the Lear jet. Quart. J. Roy. Meteor. Soc., 125, 3189-3217.

Szunyogh, I., Z. Toth, R. E. Morss, S. J. Majumdar, B. J. Etherton, and C. H. Bishop, 2000: The effect of targeted dropsonde observations during the 1999 winter storm reconnaissance program. Mon. Wea. Rev., 128, 3520-3537.

Szunyogh, I., Z. Toth, A. V. Zimin, S. J. Majumdar, and A. Persson, 2002: Propagation of the effect of targeted observations: The 2000 Winter Storm Reconnaissance program. Mon. Wea. Rev., 130, 1144-1165.

Toth, Z., and S. J. Majumdar, 2007: NOAA THORPEX science workshop. Bull. Amer. Meteor. Soc., 88, 717719. http://www.ucar.edu/na-thorpex/

Yoneyama, K., Y. Masumoto, Y. Kuroda, M. Katsumata, K. Mizuno, Y. Takayabu, M. Yoshizaki, A. Shareef, Y. Fujiyoshi, M. J. McPhaden, V. S. N. Murty, R. Shirooka, K. Yasunaga, H. Yamada, N. Sato, T. Ushiyama, Q. Moteki, A. Seiki, M. Fujita, K. Ando, H. Hase, I. Ueki, T. Horii, C. Yokoyama, and T. Miyakawa, 2007: Overview and early results of the MISMO field experiment. Bull. Amer. Meteor. Soc., (submitted). http://www . jamstec.go.jp/iorgc/ mismo/, http://www.jamstec.go.jp/iorgc/primo/

Manuscript received 23 July 2007, accepted 19 September 2007 SOLA: http://www.jstage.jst.go.jp/browse/sola/ 